Wataru Matsuyama - Masanori Nakagawa

Takashi Moritoyo - Hiroshi Takashima - Fujio Umehara

Keiko Hirata • Masahito Suehara • Mitsuhiro Osame

\title{
Phenotypes of X-linked Charcot-Marie-Tooth disease and altered trafficking of mutant Connexin 32 (GJB1)
}

\begin{abstract}
To clarify the pathomechanism in three patients with X-linked Charcot-Marie-Tooth disease (CMTX) and unique clinical features, we studied three connexin $(C x) 32$ (GJB1) mutants with respect to cellular localization in cultured cells. Wild-type $C x 32$ and three $C x 32$ mutants (Val63Ile and Glu186Lys, obtained from CMTX patients with hearing impairment; and Arg22Gln, obtained from a CMTX patient with a fair number of onion-bulb formations) were transfected to rat pheochromocytoma cells (PC12). We investigated the expression of Cx32 protein in each clone by immunoblotting and immunohistochemical staining. While $\mathrm{C} \times 32$ protein with the Arg22Gln mutation was detectable immunohistochemically only in the cytoplasm, Cx32 protein with the Val63Ile or Glu186Lys mutation was detected in both the plasma membrane and the cytoplasm. Cx32 protein with the wild-type sequence was detected mostly in the plasma membrane, with plaques indicating the existence of active gap junction formation. These three $C x 32$ mutations associated with CMTX patients with unique clinical and pathological findings caused altered trafficking of the $\mathrm{Cx} 32$ protein. These altered expressions indicated loss of active gap junction formation with different expression abnormalities in these CMTX patients.
\end{abstract}

Key words Connexin $32 \cdot \mathrm{CMTX} \cdot$ Hearing impairment . Onion-bulb formation $\cdot \mathrm{PC} 12 \cdot$ Expression study

W. Matsuyama $\cdot$ M. Nakagawa $(\bowtie) \cdot$ T. Moritoyo $\cdot$ H. Takashima F. Umehara $\cdot$ M. Osame

Third Department of Internal Medicine, Kagoshima University

Faculty of Medicine, 8-35-1 Sakuragaoka, Kagoshima 890-8520,

Japan

Tel. +81-992-75-5332; Fax +81-992-65-7164

e-mail: nakagawa@m2.kufm.kagoshima-u.ac.jp

T. Moritoyo

First Department of Physiology, Kagoshima University Faculty of Medicine, Kagoshima, Japan

K. Hirata $\cdot$ M. Suehara

Department of Neurology, National Sanatorium Okinawa Hospital,

Okinawa, Japan

\section{Introduction}

X-Linked Charcot-Marie-Tooth disease (CMTX, MIM302800) is an X-linked dominant disorder characterized by moderate-to-severe motor and sensory neuropathy, and is caused by mutations in the gene for connexin 32 (Cx32; GJB1) (Skre 1974; Bergoffen et al. 1993; Ionasescu 1995; Fischbeck et al. 1996; Bone et al. 1997). Affected males show a form of hereditary motor and sensory neuropathy, with clinical features that include progressive weakness and atrophy of distal limb muscles, loss of reflexes, sensory loss, and reduced nerve conduction velocity (Skre 1974; Fischbeck et al. 1996; Bone et al. 1997). Cx32 is a gap junction protein found mainly in the paranodal regions and the Schmidt-Lanterman incisures of peripheral nerve myelin; six connexin molecules assemble to form one connexon and act as gap junction channels providing direct intercellular communications (Bergoffen et al. 1993; Scherer et al. 1995). Since 1993, more than 200 different mutations, affecting every portion of the gene (Bergoffen et al. 1993, Fairweather et al. 1994; Ionasescu 1995; Ionasescu et al. 1994, 1996; Bone et al. 1995, 1997; Fischbeck et al. 1996; Janssen et al. 1997; Birouk et al. 1998; Sander et al. 1998; Nelis et al. 1999; Hahn et al. 1999), have been identified. However, only several mutations have been investigated in terms of their ability to form functional gap junctions and in terms of their relations with other connexins (Bruzzone et al. 1994; Omori et al. 1996; Deschênes et al. 1997; Oh et al. 1997; Ressot et al. 1998; Sahenk and Chen 1998; Nicholson and Corbett 1999; Fischbeck et al. 1999).

Hearing impairment and other central nervous system (CNS) symptoms have been reported in CMTX patients with several types of $C x 32$ mutations (Nicholson and Corbett 1996; Nicholson et al. 1998; Bähr et al. 1999; Stojkovic et al. 1999). One of the common sural nerve findings in CMTX is a loss of myelinated fibers, especially large fibers, and thin myelination. However, onion-bulb formations are frequently observed in CMTX patients with several types of Cx32 mutations (Sander et al. 1998; Senderek 
et al. 1998). The relationship between these clinical and pathological phenotypes and the expression pattern of the Cx32 mutations has not previously been studied. To clarify the correlation of these clinical phenotypes and $C x 32$ mutations, we investigated the relationship between the clinical features and the expression pattern of the Cx32 mutations. We established clones of rat pheochromocytoma cells (PC12), a communication-incompetent mammalian cell line, stably expressing Cx32 mutant obtained from three unique CMTX patients (with mental retardation and sensorineural deafness, severe sensorineural deafness, and a fair number of onion-bulb formations in sural nerve biopsy specimens) and examined the cells immunohistochemically.

\section{Subjects and methods}

\section{Clinical features of CMTX patients}

The following Cx32 mutations were examined in this study: Arg22Gln, Val63Ile, and Glu186Lys. The phenotypes and pathological findings of the CMTX patients bearing these mutations are summarized in Table 1 . The characteristic features of these patients were as follows.

Patient 1 (Arg22Gln mutation), a 36-year-old man, had muscle weakness in the distal lower limbs when he was of elementary school age. He had gait disturbance at the age of 30 and was referred to our hospital at the age of 33. On admission, he showed typical clinical symptoms of CMT1, but had no cranial nerve involvement. His hearing function was normal. Sural nerve biopsy specimen showed relatively thin myelin sheaths, a fair number of onion-bulb forma- tions, and clusters of thinly myelinated, regenerating nerve fibers surrounded by concentric Schwann cell processes.

Patient 2 (Val63Ile mutation), a 60-year-old man, had had finger deformities, muscle atrophy in the upper limbs, and short stature since childhood. His comprehensive ability at elementary and junior high-school ages was below normal. He had recognized hearing impairment since the age of 55. He had gait disturbance at the age of 30, and difficulty in moving his fingers because of finger contracture around the age of 50. His muscle weakness in the extremities became prominent at the age of 57. He underwent an operation for cataract and retinal detachment of the right eye at the age of 59. A detailed family study was not available, but none of his family members had similar clinical symptoms. On examination at the age of 60 , he had low intelligence (IQ, 72), saccadic eye movement, sensorineural deafness $(-35 \mathrm{~dB}$ at $250 \mathrm{~Hz})$, and distal dominant muscle weakness, including finger flexion contracture and pes cavus. The muscle weakness in the upper limbs was more prominent than that in the lower limbs. He had no sensory disturbance in the extremities. Sensory nerve conduction velocities were within normal ranges. The latency of waves I-III in brainstem auditory evoked potentials (BAEPs) was at the upper limit of the normal range. Brain magnetic resonance imaging (MRI) and computed tomography (CT) did not show any specific abnormalities.

Patient 3 (Glu186Lys mutation) had hearing impairment at the age of 6 and started to use a hearing aid at the age of 12. He had gait disturbance at the age of 20 . He was suspected of having chronic inflammatory demyelinating polyneuropathy at the age of 38 because of peripheral neuropathy with increased protein level in cerebrospinal fluid $(65 \mathrm{mg} / \mathrm{dl})$. Prednisolone therapy was not effective, and he was referred to our hospital at the age of 39 . He had

Table 1. Clinical features of the investigated CMTX patients with $C x 32$ mutations and cellular localization of Cx32 protein expressed in PC12 cells

\begin{tabular}{|c|c|c|c|}
\hline Patient & 1 & 2 & 3 \\
\hline Mutation site & Arg22Gln & Val63Ile & Glu186Lys \\
\hline Age/Sex & 36/Male & 60/Male & 40/Male \\
\hline Age at disease onset (years) & 10 & 30 & 6 \\
\hline \multicolumn{4}{|l|}{ Neurological symptoms } \\
\hline Intelligence test & MMSE 30/30 & WAIS-R; IQ, 72 & MMSE 30/30 \\
\hline Hearing impairment & None & $-35 \mathrm{~dB}$ at $250 \mathrm{~Hz}$ & $-40 \mathrm{~dB}$ at $250 \mathrm{~Hz}$ \\
\hline Muscle strength of distal lower limbs & 2 & $2-3$ & 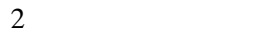 \\
\hline Sensory disturbance & Yes & None & Yes \\
\hline \multicolumn{4}{|l|}{ Nerve conduction study } \\
\hline Median nerve MCV (m/s) & 27.9 & 41.2 & 38.0 \\
\hline $\operatorname{SCV}(\mathrm{m} / \mathrm{s})$ & 29.3 & 46.7 & $\mathrm{NE}$ \\
\hline Tibial nerve MCV (m/s) & 14.8 & 37.0 & 27.9 \\
\hline Sural nerve SCV $(\mathrm{m} / \mathrm{s})$ & $\mathrm{NE}$ & 48.2 & $\mathrm{NE}$ \\
\hline \multicolumn{4}{|l|}{ Pathological findings in sural nerve ${ }^{\mathrm{b}}$} \\
\hline Thin myelin & + & ++ & ++ \\
\hline Onion-bulb formations & +++ & + & \pm \\
\hline Cellular localization of $\mathrm{Cx} 32$ protein expressed in $\mathrm{PC} 12$ & Cytoplasm & $\begin{array}{l}\text { Plasma membrane } \\
\text { and cytoplasm }\end{array}$ & $\begin{array}{l}\text { Cytoplasm and } \\
\text { plasma membrane }\end{array}$ \\
\hline
\end{tabular}

CMTX, X-linked Charcot-Marie-Tooth disease; MCV, motor nerve conduction velocity; SCV, Sensory nerve conduction velocity; MMSE, mini mental state examination; WAIS-R, Wechsler adult intelligence scale-revised; NE, Not evoked

${ }^{a}$ Muscle strength is described as follows: 5 , normal; 4, good; 3 , fair; 2 , poor; 1 , trace

${ }^{\mathrm{b}}$ The frequencies of each pathological feature are described as follows: \pm , few; + , occasional;,++ fair; +++ , abundant 
distal dominant muscle atrophy and weakness, sensory disturbance, facial muscle weakness, and sensorineural deafness $(-40 \mathrm{~dB}$ at $250 \mathrm{~Hz})$. He had no remarkable family history, except that his 61-year-old mother had diabetes mellitus, without muscle weakness or atrophy. Her motor nerve conduction velocity was normal, but her sensory nerve conduction velocity was at the lower limit of the normal range.

Preparation of plasmid constructs carrying genomic DNA coding for wild-type and mutant $C \times 32$

The coding regions of wild-type and mutant $C x 32$ of the genomic DNA of an unaffected man and of the CMTX patients, respectively, were amplified by polymerase chain reaction (PCR; one cycle at $94^{\circ} \mathrm{C}$ for $5 \mathrm{~min} ; 30$ cycles at $94^{\circ} \mathrm{C}$ for $1 \mathrm{~min}, 60^{\circ} \mathrm{C}$ for $1 \mathrm{~min}$, and $72^{\circ} \mathrm{C}$ for $1 \mathrm{~min}$ ) with $\mathrm{LA}$ Taq polymerase (Takara Shuzo, Tokyo, Japan) in a Gene Amp PCR System 9700 thermal controller (PE Aplied Biosystems, Foster City, CA, USA). The following primers, with restriction sites used to amplify a segment containing the translational start site (nucleotides -6 to 14) and stop codon (nucleotides 920 - 939) were applied to the PCR: sense Cx32F.Kpn 5'-CGGGGTACCGGCAGGATG AACTGGACAGG-3' and antisense Cx32R.Bam 5'GGCGGATCCATGGCAGGTTGCCTGGTATG-3' (Deschênes et al. 1997). After purification, using Geneclean (BIO 101, Vista, CA, USA), the PCR products were digested with $K p n \mathrm{I}$ and $B a m \mathrm{HI}$ and ligated into the $K p n \mathrm{I}$ and BamHI site of pREP9 (Invitrogen, San Diego, CA, USA). The constructs were sequenced on both strands at least twice to verify the sequence, using an ABI PRISM 310 autosequencer (PE Applied Biosystems).

\section{Cell culture and stable transfection}

The subclone of rat PC12 cells used in this study expressed no endogenous Cx32 protein or mRNA (data not shown). These cells were cultured in RPMI 1640 medium (Nikken Biomedical Laboratory, Kyoto, Japan), supplemented with $10 \%$ horse serum, $5 \%$ fetal bovine serum, penicillin, and streptomycin in a $37^{\circ} \mathrm{C}, 5 \% \mathrm{CO}_{2}$ incubator. The PC12 cells were stably transfected with 5-35 $\mu$ g of plasmid DNA of various Cx32 mutants and Lipofectin reagent (Life Technologies, Gaithersburg, MD, USA), according to the manufacturer's protocol. Three days after transfection, selection was started with G418 $(400 \mu \mathrm{g} / \mathrm{ml}$, Life Technologies) and independent clones were randomly picked up 3 weeks after the selection.

\section{Immunoblotting analysis}

The cells grown to confluence were harvested and lysed directly in ice-cold $50 \mathrm{mM}$ Tris, $\mathrm{pH} 7.0,1 \%$ sodium dodecylsulfate (SDS), and $0.017 \mathrm{mg} / \mathrm{ml}$ phenylmethylsulfonyl fluoride (Sigma, St. Louis, MO, USA), followed by brief sonication on ice with a sonic dismembrator (UD200; Tomy, Tokyo, Japan). Rat liver homogenate, prepared with a steel mortar in $20 \mathrm{mM} \mathrm{NaOH}$, with sonication, was used as a control. A 100- $\mu \mathrm{g}$ sample of protein lysate for each clone and $1 \mu \mathrm{l}$ of the rat liver homogenate were loaded onto $12.5 \%$ SDS-polyacrylamide gels after a $10-\mathrm{min}$ incubation in sample buffer at room temperature. Then, they were electrophoresed and transferred to an Immobilon polyvinylidene fluoride membrane (Millipore, Bedford, MA, USA), using a semidry blotting unit (Bio-RAD, Hercules, CA, USA) following Millipore's recommendations. After being washed in blocking solution, the blots were incubated at $4{ }^{\circ} \mathrm{C}$ overnight with a monoclonal antibody for Cx32 (M12.13) (Chemicon International Temecula, CA, USA) diluted to 1:100. After being washed with phosphate-buffered saline (PBS)-Tween-20 (PBT), the blots were incubated with biotinated secondary antibody against mouse IgG (Biogenex, San Ramon, CA, USA) and visualized with strep-tavidin conjugated to horseradish peroxidase (Biogenex) and diaminoben zedine (DAB).

\section{Immunohistochemistry}

Eight-well plastic chamber slides (Lab-Tek Permanoxcoated slides; Nunc, Naperville, IL, USA) were coated with $10 \mu \mathrm{g} / \mathrm{ml}$ poly-L-lysine (Sigma), air-dried, and seeded with clones expressing the three $C x 32$ mutants. Twenty clones for each mutation were picked up and seeded on the slides. When cells reached $75 \%$ confluence, they were fixed in $95 \%$ ethanol $/ 5 \%$ glacial acetic acid at $-20^{\circ} \mathrm{C}$ for $10 \mathrm{~min}$. After being washed in PBS without calcium or magnesium ions, the slides were blocked in 5\% bovine serum albumin, $10 \%$ fetal bovine serum, $0.1 \%$ Triton X-100, $0.1 \mathrm{M} \mathrm{NaH}_{2} \mathrm{PO}_{4}$, $0.1 \mathrm{M} \mathrm{Na}_{2} \mathrm{HPO}_{4}$ and $0.01 \%$ sodium azide at $37^{\circ} \mathrm{C}$ for $60 \mathrm{~min}$. Incubations in the following antibodies were done at $4^{\circ} \mathrm{C}$ for $72 \mathrm{~h}$ in a humidified chamber: a monoclonal antibody for Cx32 (M12.13; Chemicon International) diluted to 1:10 and a monoclonal antibody against rat liver Golgi $\alpha$ mannosidase II (Covance, Richmond, CA, USA) diluted to 1:500. After being washed in PBS, slides were incubated with 1:100 diluted biotinylated secondary antibody against mouse IgG for $60 \mathrm{~min}$. The slides were again rinsed in PBS and incubated in fluorescein-conjugated streptavidin antibody (Dako, Carpinteria, CA, USA) diluted to 1:50. The slides were mounted in Vectashield (Vector Laboratories, Burlingame, CA, USA) and visualized with a scanning laser confocal microscope (Leica, Nussloch, Germany), using Scan Ware 5.10 software (Leica, Nussloch, Germany) to generate optical sections that were $1 \mu \mathrm{m}$-thick or less.

\section{Results}

Immunoblotting analysis

All PC12 cells that were transfected with wild-type Cx32 and the $\mathrm{C} \times 32$ mutants expressed $\mathrm{C} \times 32$ protein, although the migration distances of these mutants were slightly different (Fig. 1). 


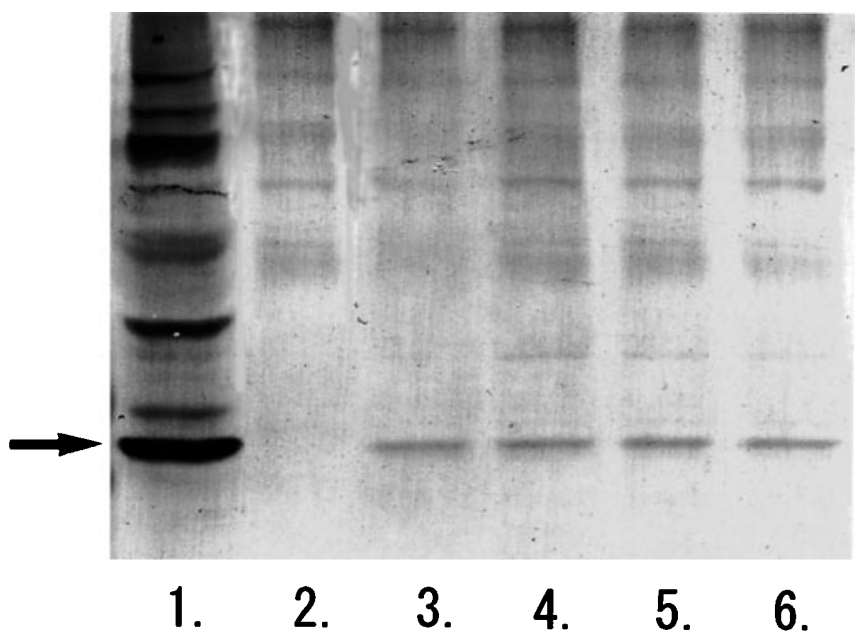

Fig. 1. Immunoblotting analysis of the $\mathrm{Cx} 32$ protein obtained from PC12 cells. Lane 1, positive control (rat liver); lane 2, PC12 cells; lane 3 , wild-type $C x 32$; lane 4, mutant $C x 32$ with Arg22Gln; lane 5, mutant Cx32 with Val63Ile; lane 6, mutant Cx32 with Glu186Lys. All the clones produced $\mathrm{Cx} 32$ protein, and the molecular sizes were similar to those of normal Cx32 protein (arrow). Lanes 5 and 6, however, suggested a higher molecular weight $\mathrm{Cx} 32$ protein than normal in these clones, although the differences were very small

Immunohistochemical analysis

Cells expressing wild-type $C x 32$ had plaque and punctate staining, especially in regions of cell-cell contact (Fig. 2A). The clone expressing the Arg22Gln mutant showed a cytoplasmic pattern overlapping with the Golgi apparatus (Fig. 2B). These findings were confirmed by the double staining of the cells with antibodies for $\mathrm{Cx} 32$ and $\alpha$-mannosidase II (Fig. 2E). In the cells expressing the Val63Ile mutant, the Cx32 protein was localized in the plasma membrane in a punctate, or plaque-like, staining pattern, with cytoplasmic staining to some extent (Fig. 2C). PC12 cells transfected with Glu186Lys showed diffuse cytoplasmic staining, with plasma membrane staining to some extent. The cytoplasmic staining overlapped, but was not limited to, the Golgi apparatus (Fig. 2D).

The incidence of positively stained clones in the 20 surviving clones with each mutation under selective pressure was as follows: 15 clones with wild type $C x 32$ (Fig. 2A), 17 with the Arg22Gln mutation (Fig. 2B), 14 with the Val63Ile mutation (Fig. 2C), and 16 with the Glu186Lys mutation (Fig. 2D).

\section{Discussion}

A correlation between $C x 32$ mutations and disease severity in CMTX has been suggested, but is still controversial in some aspects (Fairweather et al. 1994; Ionasescu 1995; Ionasescu et al. 1994, 1996; Fischbeck et al. 1996; Bone et al. 1995, 1997; Janssen et al. 1997; Birouk et al. 1998; Sander et al. 1998; Nelis et al. 1999; Hahn et al. 1999, Nicholson et al. 1999). A dominant negative effect, loss of function effect, and interaction among different connexins have been proposed to explain the molecular mechanism of the genotype/ phenotype correlation in CMTX (Omori et al. 1996; Deschênes et al. 1997; Oh et al. 1997; Ressot et al. 1998; Sahenk and Chen 1998; Hahn et al. 1999; Nicholson et al. 1999; Fischbeck et al. 1999). However, it is uncertain whether the patients with mutant $C \times 32$ who were investigated in the expression study of mutant $C x 32$ in culture cells showed unusual symptoms of CMTX, such as CNS involvement (Bruzzone et al. 1994; Omori et al. 1996; Deschênes et al. 1997; Oh et al. 1997; Ressot et al. 1998; Sahenk and Chen 1998; Nicholson et al. 1999; Fischbeck et al. 1999).

In the present study, we constructed clones with mutant Cx32 to study the genotype/phenotype correlation in three CMTX patients with unique clinical and pathological findings. Based on the immunohistochemical analysis we conducted, we found that the three $C \times 32$ mutants showed two expression patterns; diffuse staining of the cytoplasm, and staining of both the plasma membrane and cytoplasm with variable intensity. In the mutant Val63Ile, which is in the extracellular domain, the Cx32 protein was localized both in the plasma membrane and cytoplasm. This pattern was relatively similar to that reported by Deschênes et al. (1997). The staining pattern of the mutant Glu186Lys was mainly cytoplasmic, with plasma membrane staining to some extent. A previous study of the Glu186Lys mutant in PC12 cells showed an entirely cytoplasmic staining pattern in clones expressing Glu186Lys (Deschênes et al. 1997). These differences are probably caused by the use of different monoclonal antibodies against $C x 32$ for immunohistochemical staining.

As two of the patients in this study had sensorineural hearing impairment, the mutation of Cx32 at the sites of Val63Ile and Glu186Lys may be relevant to the failure of functional gap junction formation, or a fraction of the protein misrouted to Schwann cells may be related to hearing function in the CNS. Because connexins are present in the CNS (Nadarajah et al. 1996; Dermietzel et al. 1997), CNS abnormalities, including hearing impairment, are assumed to be based on the direct effects of $C \times 32$ mutations or to be the results of interactions with other types of connexins. However, we need to conduct further investigations, such as electrophysiological and dye-coupling studies and examination of the mutant protein in the myelin sheath, in order to prove the specific effect of this mutation in the function of gap junctions.

The patient with the Val63Ile mutation had mental retardation in addition to the hearing impairment. As no patient with CMTX has yet been reported to show associated mental retardation, it is possible that the mental retardation in this patient may not be related to the $C x 32$ mutation.

In the mutant Arg22Gln, diffuse cytoplasmic staining, overlapping with Golgi apparatus, was observed, without cell surface staining. This finding is consistent with that of a previous study that demonstrated no channel-forming activity in Arg22Gln antisense-treated oocytes (Ressot et al. 1998). In the patient with this mutation, the phenotypic characteristies were the most severe of those in the three 

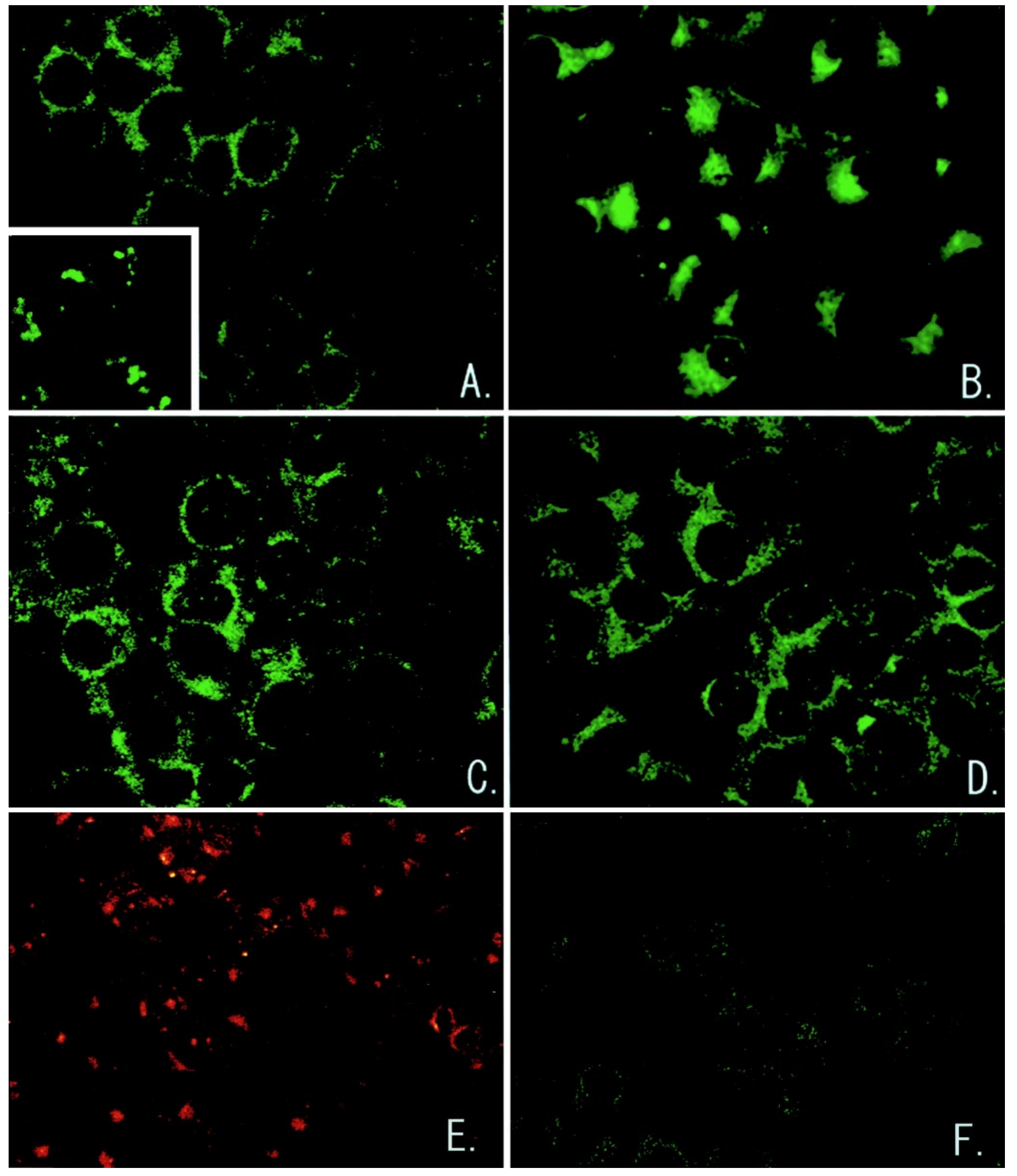

Fig. 2A-F. Immunohistochemical appearance of the $\mathrm{Cx} 32$ protein in PC12 cells transfected by $C x 32$ stained with monoclonal antibody against Cx32 (M12.13) (green color, except in $\mathbf{E}$ ), using scanning laser confocal microscopy. A Wild-type Cx32; B Cx32 with Arg22Gln mutation; C Cx32 with Val63Ile mutation; D Cx32 with Glu186Lys mutation; $\mathbf{E}$ superimposed findings of double staining with antibodies for Cx32 (red) and $\alpha$-mannosidase II (green) in cells with the Arg22Gln mutation; F PC12 cells alone. A The wild-type $C x 32$ clone shows plaque and punctate staining, especially in regions of cell-cell contact (inset). B The Arg22Gln mutant shows diffuse cytoplasmic staining overlapping the Golgi apparatus. E Double staining with antibodies for Cx32 (red) and $\alpha$-mannosidase II (green) confirmed the overlapping of the mutant $\mathrm{Cx} 32$ protein and the Golgi apparatus (yellow). C The Val63Ile mutant shows plasma membrane staining, with cytoplasmic staining to some extent. D The Glu186Lys mutant shows diffuse cytoplasmic staining, with plasma membrane staining to some extent. The negative control showed background staining to some extent $(\mathbf{F})$, but the intensity appeared to differ from that in the positive staining $(\mathbf{B}, \mathbf{C}, \mathbf{D})$ 
patients, and sural nerve biopsy showed a fair number of onion-bulb formations and clusters of thinly myelinated, regenerating nerve fibers surrounded by concentric Schwann cell processes. Senderek et al. (1998) have also reported a patient with the Arg22Gln mutation and onionbulb formation. Therefore, this mutation (Arg22Gln) seemed to be related to onion-bulb formation in CMTX, probably through an abnormal myelinating function in Schwann cells. This mutation is one of the hot spots of $C \times 32$ mutations (Nelis et al. 1999), and more than six patients with this mutation have been reported. However, the pathological findings in the sural nerve were not described, except in the patient reported by Senderek et al. (1998). Our speculation would be confirmed if the pathological findings were observed in other patients with this mutation. Arg22 is one of the transmembrane domain components of Cx32, and the two other mutation sites represent extracellular components (Bruzzone et al. 1996). This suggests that the accumulation of aberrantly trafficked mutant protein in the Golgi apparatus could have deleterious or toxic gainof-function effects on Schwann cell metabolism.

In the present study, we showed, in vitro, that the three mutations Arg22Gln, Val63Ile, and Glu186Lys, in CMTX patients with unique clinical features had an altered trafficking effect on $\mathrm{Cx} 32$ protein expression. This phenomenon was assumed to have some association with the phenotype and pathomechanism in the CMTX patients studied. However, it is still difficult to draw definitive conclusions based only on the present study. Many other mechanisms, caused by various mutations, may exist in CMTX, and further studies addressing these points, examining various other mutations, may clarify the underlying molecular mechanism and the interaction of $C \times 32$ mutants with other connexins in CMTX.

Acknowledgments This work was supported, in part, by a Research Grant (10B-4) for Nervous and Mental Disorders, and a Research Grant (6-2A) for Central Nervous System Degenerative Disorders from the Ministry of Health, Labour, and Welfare of Japan. The authors thank Ms. S. Taniguchi and Ms. M. Miyazaki of Kagoshima University for their excellent technical assistance.

\section{References}

Bähr M, Andres F, Timmerman V, Nelis ME, Van Broeckhoven C, Dichgans J (1999) Central visual, acoustic, and motor pathway involvement in a Charcot-Marie-Tooth family with an Asn205Ser mutation in the connexin 32 gene. J Neurol Neurosurg Psychiatry 66:202-206

Bergoffen J, Scherer SS, Wang S, Scott MO, Bone LJ, Paul DL, Chen K, Lensch MW, Chance PF, Fischbeck KH (1993) Connexin mutations in X-Linked Charcot-Marie-Tooth disease. Science 262:20392042

Birouk N, LeGuern E, Maisonobe T, Rouger H, Gouider R, Tardieu S, Gugenheim M, Routon MC, Leger JM, Agid Y, Brice A, Bouche P (1998) X-Linked Charcot-Marie-Tooth disease with connexin 32 mutations: clinical and electrophysiologic study. Neurology 50:10741082

Bone LJ, Dahl N, Lensch MW, Chance PF, Kelly T, Le Guern E, Magi S, Parry G, Shapiro H, Wang S, Fischbeck KH (1995) New connexin 32 mutations associated with X-linked Charcot-Marie-Tooth disease. Neurology 45:1863-1866
Bone LJ, Deschênes SM, Balice-Gordon RJ, Fischbeck KH, Scherer SS (1997) Connexin 32 and X-linked Charcot-Marie-Tooth disease. Neurobiol Dis 4:221-230

Bruzzone R, White TW, Scherer SS, Fischbeck KH, Paul DL (1994) Null mutations of connexin 32 in patients with X-linked CharcotMarie-Tooth disease. Neuron 13:1253-1260

Bruzzone R, White TW, Paul DL (1996) Connections with connexins: the molecular basis of direct intercellular signaling. Eur J Biochem 238:1-27

Dermietzel R, Farooq M, Kessler JA, Althaus H, Hertzberg EL, Spray DC (1997) Oligodendrocytes express gap junction proteins connexin 32 and connexin 45. Glia 20:101-114

Deschênes SM, Walcott JL, Wexler TL, Scherer SS, Fischbeck KH (1997) Altered trafficking of mutant connexin 32. J Neurosci 17:9077-9084

Fairweather N, Bell C, Cochrane S, Chelly J, Wang S, Mostacciuolo ML, Monaco AP, Haites NE (1994) Mutations in the connexin 32 gene in X-linked dominant Charcot-Marie Tooth disease (CMTX1). Hum Mol Genet 3:29-34

Fischbeck KH, Deschênes SM, Bone LJ, Scherer SS (1996) Connexin 32 and X-linked Charcot-Marie-Tooth disease. Cold Spring Harb Symp Quant Biol 61:673-677

Fischbeck KH, Abel A, Lin GS, Scherer SS (1999) X-Linked Charcot-Marie-Tooth disease and connexin 32. Ann NY Acad Sci 883:36-41

Hahn AF, Bolton CF, White CM, Brown WF, Tuuha SE, Tan CC, Ainsworth PJ (1999) Genotype/Phenotype correlations in X-linked dominant Charcot-Marie-Tooth disease. Ann NY Acad Sci 883:366382

Ionasescu VV (1995) Charcot-Marie-Tooth neuropathy: from clinical description to molecular genetics. Muscle Nerve 18: 267-275

Ionasescu V, Searby C, Ionasescu R (1994) Point mutations of connexin 32 (GJB1) gene in X-linked dominant Charcot-MarieTooth neuropathy. Hum Mol Genet 3:355-358

Ionasescu V, Ionasescu R, Searby C (1996) Correlation between connexin 32 gene mutations and clinical phenotype in X-linked dominant Charcot-Marie-Tooth neuropathy. Am J Med Genet 63:486-491

Janssen EA, Kemp S, Hensels GW, Sie OG, de Die-Smulders CE, Hoogendijk JE, de Visser M, Bolhuis PA (1997) Connexin 32 gene mutations in X-linked dominant Charcot-Marie-Tooth disease (CMTX1). Hum Genet 99:501-505

Nadarajah B, Thomaidou D, Evans WH, Parnavelas JG (1996) Gap junctions in the adult cerebral cortex: regional differences in their distribution and cellular expression of connexins. J Comp Neurol 376:326-342

Nelis E, Haites N, Van Broeckhoven C (1999) Mutations in the peripheral myelin genes and associated genes in inherited peripheral neuropathies. Hum Mutat 13:11-28

Nicholson GA, Corbett A (1996) Slowing of central conduction in Xlinked Charcot-Marie-Tooth neuropathy shown by brain stem auditory evoked responses. J Neurol Neurosurg Psychiatry 61:43-46

Nicholson SM, Ressot C, Gomès D, D'Andrea P, Perea J, Duval N, Bruzzone R (1999) Connexin 32 in the peripheral nervous system. Functional analysis of mutations associated with X-linked CharcotMarie-Tooth syndrome and implications for the pathophysiology of the disease. Ann N Y Acad Sci 883:168-185

Nicholson GA, Yeung L, Corbett A (1998) Efficient neurophysiologic selection of X-linked Charcot-Marie-Tooth families: ten novel mutations. Neurology 51:1412-1416

Oh S, Ri Y, Bennett MV, Trexler EB, Verselis VK, Bargiello TA (1997) Changes in permeability caused by connexin 32 mutations underlie X-linked Charcot-Marie-Tooth disease. Neuron 19:927-938

Omori Y, Mesnil M, Yamasaki H (1996) Connexin 32 mutations from $\mathrm{X}$-linked Charcot-Marie-Tooth disease patients: functional defects and dominant negative effects. Mol Biol Cell 7:907-916

Ressot C, Gomès D, Dautigny A, Pham-Dinh D, Bruzzone R (1998) Connexin 32 mutations associated with X-linked Charcot-MarieTooth disease show two distinct behaviors: loss of function and altered gating properties. J Neurosci 18:4063-4075

Sahenk Z, Chen L (1998) Abnormalities in the axonal cytoskeleton induced by a connexin 32 mutation in nerve xenografts. J Neurosci Res 51:174-184

Sander S, Nicholson GA, Ouvrier RA, McLeod JG, Pollard JD (1998) Charcot-Marie-Tooth disease: histopathological features of the 
peripheral myelin protein (PMP22) duplication (CMT1A) and connexin 32 mutations (CMTX1). Muscle Nerve 21:217-225

Scherer SS, Deschênes SM, Xu Y, Grinspan JB, Fischbeck KH, Paul DL (1995) Connexin 32 is a myelin-related protein in the PNS and CNS. J Neurosci 15:8281-8294

Senderek J, Bergmann C, Quasthoff S, Ramaekers VT, Schroder JM (1998) X-Linked dominant Charcot-Marie-Tooth disease: nerve bi- opsies allow morphological evaluation and detection of connexin 32 mutations (Arg15Trp, Arg22Gln). Acta Neuropathol 95: 443-449

Skre H (1974) Genetic and clinical aspects of Charcot-Marie-Tooth disease. Clin Genet 6:98-118

Stojkovic T, Latour P, Vandenberghe A, Hurtevent JF, Vermersch P (1999) Sensorineural deafness in X-linked Charcot-Marie-Tooth disease with connexin 32 mutation (R142Q). Neurology 52:1010-1014 